\title{
Article \\ Fatty Acids Quality in Middle Eastern Traditional Dishes, Arabic Sweets and Market Foods Frequently Consumed in Lebanon
}

\author{
Maha Hoteit ${ }^{1}$, Edwina Zoghbi ${ }^{2}$, Alissar Rady ${ }^{2}$, Iman Shankiti ${ }^{2}$ and Ayoub Al-Jawaldeh ${ }^{3, * \text { (D) }}$ \\ 1 Faculty of Public Health, Lebanese University, Beirut 6573, Lebanon; m.hoteit@ul.edu.lb \\ 2 Country Office for Lebanon, World Health Organization, Beirut 5391, Lebanon; zoghbie@who.int (E.Z.); \\ Radya@who.int (A.R.); shankitii@who.int (I.S.) \\ 3 World Health Organization Regional Office for the Eastern Mediterranean, Cairo 11371, Egypt \\ * Correspondence: aljawaldeha@who.int
}

check for updates

Citation: Hoteit, M.; Zoghbi, E.; Rady, A.; Shankiti, I.; Al-Jawaldeh, A. Fatty Acids Quality in Middle Eastern Traditional Dishes, Arabic Sweets and Market Foods Frequently Consumed in Lebanon. Nutrients 2021, 13, 2462. https://doi.org/10.3390/nu13072462

Academic Editor: Lindsay Brown

Received: 24 June 2021

Accepted: 9 July 2021

Published: 19 July 2021

Publisher's Note: MDPI stays neutral with regard to jurisdictional claims in published maps and institutional affiliations.

Copyright: (c) 2021 by the authors. Licensee MDPI, Basel, Switzerland. This article is an open access article distributed under the terms and conditions of the Creative Commons Attribution (CC BY) license (https:// creativecommons.org/licenses/by/ $4.0 /)$.

\begin{abstract}
The prevalence of diet-related non-communicable diseases is on the rise in the countries of the Eastern Mediterranean, including Lebanon. This study aimed to provide data on fatty acid profiles and ratios of Lebanese composite dishes, Arabic sweets, and market foods. Methods: Thirty types of traditional dishes, collected from five different Lebanese governorates, thirty-seven types of Arabic sweets and forty-six market food products were considered for analysis. Food samples were chemically analyzed for total, unsaturated and saturated fatty acids. The range of total fatty acids in composite dishes, Arabic sweets, and market food products was between 1.2-11.7 g/100 g, 5.3-25.8 g/100 g, and 0.5-100 g/100 g, respectively. Additionally, the range of saturated fatty acids in composite dishes, Arabic sweets, and market food products was between 0.5-4.9 g/100 g, 2.5-23.6 g/100 g and 0.1-56.4 g/100 g, respectively. Furthermore, about 75\% of these foods were poor in unsaturated fatty acids. Regarding saturated fatty acid, the polyunsaturated to monounsaturated (P.M.S) ratio was lower than the recommended ratio of $1: 1: 1$ in $96 \%$ of samples. To conclude, there is a need to prioritize fat content in foods and consider processing modifications in the food production system with the aim of achieving a higher P:M:S ratio intake among the population.
\end{abstract}

Keywords: unsaturated fatty acid; saturated fatty acid; monounsaturated fatty acid; traditional dishes; Lebanon

\section{Introduction}

Diet Westernization and urbanization have led to an expansion in out-of-home meal consumption in low-middle income countries (LMICs) [1]. Nowadays, Eastern Mediterranean (EM) countries are facing rapid transitions in food patterns and development that have caused a shift in the prevalence of non-communicable diseases (NCDs) [2]. In 2018, half the worldwide population were residing in cities, and it is expected that two-thirds of humans will be urban by 2050 [3] According to the Lebanon demographics profile report in $2019,89 \%$ of the total Lebanese population was urban [4]. In Lebanese citizens, diet quality [5] and food patterns [6] were affected by this shift in urbanization. According to a study published in 2003, a representative sample of 566 Lebanese adults from five areas in Lebanon, aged 20-85 years, showed that less than $60 \%$ of the population consumed more than seven traditional dishes per week [7]. It was also observed that the majority of the Lebanese population forswears traditional cooking patterns in favor of fast-food dietary patterns [8]. The triple helix of diet, lifestyle, and chronic diseases is linked to dietary patterns and this association is well established [9]. Saturated fatty acids (SFA) that contain single carbon with carbon bonds are found in many animal and plant sources such as meat, ghee, margarine and chocolate. Concerning the monounsaturated fatty acids (MUFA), the predominant type is cis oleic acid (18:1). The following sources contain MUFA 
in abundance: nuts, avocados, and olive oil (up to 80\% MUFA). MUFAs present several health benefits, such as anti-inflammatory and cardioprotective effects and lipid profile improvement [10]. Additionally, evidence has been reported that a MUFA-rich diet instead of a high carbohydrate diet enhances the glucose tolerance of type 2 diabetes patients [11]. Regarding the polyunsaturated fatty acids (PUFA), they are essential fatty acids which are not synthesized in the body. However, PUFAs are important to be added in the diet in order to maintain good health. There are many forms of PUFAs, of which linolenic and linoleic acids are the most discussed $[12,13]$. The predominant PUFA is found in the form of linoleic acid (18:2; $n-6)$ which is present in vegetable oil, nuts, seeds, meats, and eggs. A lower proportion of PUFA is in the form of alpha-linolenic acid (18:3; $n-3)$; it is found in oily fish and green leafy vegetables [12]. There is a limited number of studies on fatty acid intake and ratios in the Eastern Mediterranean Region (EMR) [14]. Furthermore, to tackle non-communicable diseases, the planning of nutritional interventions is imperative, yet needs an assessment of the food dietary patterns and intakes of the population. However, very few dietary data instruments related to traditional dishes, Arabic sweets, and market foods intake are available in Lebanon. Thus, in response to the need for the development of culturally specific data on fatty acid content and ratios among Eastern Mediterranean citizens in order to assist healthcare professionals in evaluating the usual dietary intakes of fatty acids, this study was initiated.

\section{Materials and Methods}

\subsection{Food Selection}

A range of traditional dishes, Arabic sweets, and market foods were identified and selected for nutrient analysis. Thirty types of traditional dishes composed of many food groups, such as meats, fish, cereals, legumes, vegetables and fats, and thirty-seven types of Arabic sweets, composed of nuts, seeds, fats, cereals, dairy and sugar groups, were selected based on their frequency of consumption by the Lebanese population [8,15]. In addition, forty-six market foods were randomly selected from supermarkets regularly visited by the citizens in Beirut and Mount Lebanon areas. These foods ranged from dessert items, bakery products, local and imported on the shelf market products, coffee, and nuts. The definition of traditional 'composite dishes' is found in a previous study [16]. The names of the dishes most eaten by Lebanese citizens and chosen for this study are presented in Table 1 and their ingredients were listed previously [16]. Similarly, the lists of Arabic sweets and market foods are presented in Tables 2 and 3.

Table 1. Fatty acid ratios and total fatty acid mean values in $100 \mathrm{~g}$ of edible portions of traditional dishes and the percentage of their daily contribution in a 2000 Kcal-diet.

\begin{tabular}{|c|c|c|c|c|c|c|c|c|c|c|c|c|}
\hline \multirow{3}{*}{ Dish } & \multicolumn{4}{|c|}{ Mean Values } & \multicolumn{4}{|c|}{ Mean Values } & \multicolumn{4}{|c|}{ Mean Values } \\
\hline & \multicolumn{4}{|c|}{$\begin{array}{l}\text { Amounts in } 100 \mathrm{~g} \text { of } \\
\text { Edible Portions }\end{array}$} & \multicolumn{4}{|c|}{$\begin{array}{c}\text { Percentage of Daily } \\
\text { Contribution in } 2000 \text { Kcal Diet }\end{array}$} & \multicolumn{4}{|c|}{ Fatty Acid Ratios } \\
\hline & Fat & SFA & MUFA & PUFA & Fat & SFA & MUFA & PUFA & $P: S$ & M:S & P:M & P:M:S \\
\hline Baba ghanouj & 9.4 & 4.3 & 4.2 & 0.7 & 12.1 & 21.9 & 9.5 & 5.8 & 0.1 & 0.9 & 0.1 & $0.1: 0.9: 1$ \\
\hline Batata mahchi & 1.2 & 0.5 & 0.3 & 0.2 & 1.5 & 2.8 & 0.8 & 1.9 & 0.4 & 0.6 & 0.6 & $0.4: 0.6: 1$ \\
\hline Borgul bi banadoura & 5 & 2.4 & 1.6 & 0.9 & 6.4 & 12.3 & 3.6 & 6.9 & 0.3 & 0.6 & 0.5 & $0.3: 0.6: 1$ \\
\hline Chichbarak & 4.6 & 3.1 & 1 & 0.3 & 5.9 & 15.9 & 2.3 & 2.5 & 0.1 & 0.3 & 0.3 & $0.1: 0.3: 1$ \\
\hline Falafel & 11.7 & 4.4 & 5.4 & 1.7 & 15 & 22.4 & 12.2 & 13.6 & 0.3 & 1.2 & 0.3 & $0.3: 1.2: 1$ \\
\hline Fatayer sabanikh & 11.1 & 2.5 & 4 & 4.5 & 14.3 & 12.7 & 9.2 & 34.7 & 1.7 & 1.6 & 1.1 & $1.7: 1.6: 1$ \\
\hline Fattat Hommos & 7 & 3.6 & 2.8 & 0.5 & 9 & 18 & 6.4 & 4.3 & 0.1 & 0.7 & 0.2 & $0.1: 0.7: 1$ \\
\hline Fattoush & 2.4 & 1.7 & 0.9 & 0.2 & 3.7 & 8.7 & 2.1 & 1.6 & 0.1 & 0.5 & 0.2 & $0.1: 0.5: 1$ \\
\hline Foul moudamas & 3.4 & 1.5 & 1.7 & 0.1 & 4.4 & 7.7 & 3.9 & 1.3 & 0.1 & 1.1 & 0.1 & 0.1:1.1:1 \\
\hline Hindbe bil zet & 10.7 & 3 & 6.3 & 1.3 & 13.7 & 15.2 & 14.3 & 10.2 & 0.4 & 2 & 0.2 & $0.4: 2 .: 1$ \\
\hline Hommos bi tahini & 6.4 & 2.8 & 2.7 & 0.8 & 8.2 & 14.2 & 6.1 & 6.5 & 0.3 & 0.9 & 0.3 & 0.3:0.9:1 \\
\hline Kafta wa batata & 6.3 & 3.7 & 1.9 & 0.5 & 8.1 & 18.7 & 4.4 & 4.1 & 0.1 & 0.5 & 0.2 & $0.1: 0.5: 1$ \\
\hline Kebba bil sayniya & 6.4 & 3.7 & 1.9 & 0.6 & 8.2 & 18.6 & 4.4 & 5.1 & 0.1 & 0.5 & 0.3 & $0.1: 0.5: 1$ \\
\hline Koussa mahchi & 2.4 & 1.4 & 0.5 & 0.3 & 3.1 & 7.4 & 1.3 & 2.5 & 0.2 & 0.3 & 0.5 & $0.2: 0.3: 1$ \\
\hline Lahm bil ajin & 8.9 & 2.8 & 3.1 & 2.9 & 11.4 & 14.2 & 7.1 & 22.7 & 1 & 1.1 & 0.9 & $1: 1.1: 1$ \\
\hline Loubia bil zet & 5.6 & 1.4 & 2.7 & 1.4 & 7.2 & 7.3 & 6.1 & 11.3 & 1 & 1.8 & 0.5 & $1: 1.8: 1$ \\
\hline Malfouf mahchi & 2.1 & 1.1 & 0.6 & 0.3 & 2.7 & 5.6 & 1.4 & 2.5 & 0.3 & 0.5 & 0.5 & $0.3: 0.5: 1$ \\
\hline
\end{tabular}


Table 1. Cont

\begin{tabular}{|c|c|c|c|c|c|c|c|c|c|c|c|c|}
\hline \multirow{3}{*}{ Dish } & \multicolumn{4}{|c|}{ Mean Values } & \multicolumn{4}{|c|}{ Mean Values } & \multicolumn{4}{|c|}{ Mean Values } \\
\hline & \multicolumn{4}{|c|}{$\begin{array}{l}\text { Amounts in } 100 \mathrm{~g} \text { of } \\
\text { Edible Portions }\end{array}$} & \multicolumn{4}{|c|}{$\begin{array}{c}\text { Percentage of Daily } \\
\text { Contribution in } 2000 \text { Kcal Diet }\end{array}$} & \multicolumn{4}{|c|}{ Fatty Acid Ratios } \\
\hline & Fat & SFA & MUFA & PUFA & Fat & SFA & MUFA & PUFA & P:S & M:S & P:M & P:M:S \\
\hline Moujadara & 5.8 & 1.4 & 2.5 & 1.6 & 7.4 & 7.4 & 5.8 & 12.7 & 1.1 & 1.7 & 0.6 & $1.1: 1.7: 1$ \\
\hline Moghrabia & 3.9 & 2.2 & 1.2 & 0.4 & 5 & 11 & 2.8 & 3.2 & 0.1 & 0.5 & 0.3 & $0.1: 0.5: 1$ \\
\hline Mousaka batinjan & 6.5 & 3.4 & 2.2 & 0.8 & 8.4 & 17.1 & 5 & 6.8 & 0.2 & 0.6 & 0.4 & $0.2: 0.6: 1$ \\
\hline Riz a dajaj & 5.4 & 2.2 & 2 & 0.9 & 6.9 & 11 & 4.7 & 7.2 & 0.4 & 0.9 & 0.4 & $7.2: 0.4: 1$ \\
\hline Riz bi lahma & 6.5 & 3.4 & 2.3 & 0.6 & 8.3 & 17.3 & 5.2 & 5.3 & 0.2 & 0.6 & 0.3 & $0.2: 0.6: 1$ \\
\hline Sayadia & 6.4 & 2.4 & 2.4 & 1.5 & 8.3 & 12.2 & 5.6 & 11.7 & 0.6 & 1 & 0.6 & $0.6: 1: 1$ \\
\hline Shawarma dajaj & 6.9 & 3.2 & 2.6 & 0.9 & 8.9 & 16.4 & 6 & 7.4 & 0.2 & 0.8 & 0.3 & $0.2: 0.8: 1$ \\
\hline Shawarma lahma & 8.2 & 4.9 & 2.7 & 0.4 & 10.6 & 24.8 & 6.2 & 3.2 & 0 & 0.5 & 0.1 & $0: 0.5: 1$ \\
\hline Tabboula & 4.2 & 1.7 & 2.3 & 0.1 & 5.4 & 8.7 & 5.2 & 1.4 & 0.1 & 1.3 & 0 & 0.1:1.3:1 \\
\hline Warak enab & 3.9 & 2.4 & 1 & 0.4 & 5.1 & 12.3 & 2.3 & 3.1 & 0.1 & 0.4 & 0.3 & 0.1:0.4:1 \\
\hline Yakhnat Bamia & 5.4 & 3.7 & 1 & 0.5 & 6.9 & 18.4 & 2.4 & 4.3 & 0.1 & 0.2 & 0.5 & $0.1: 0.2: 1$ \\
\hline Yakhnat Fassoulia & 3.9 & 2.6 & 0.8 & 0.3 & 5.0 & 13.3 & 1.9 & 2.5 & 0.1 & 0.3 & 0.3 & 0.1:0.3:1 \\
\hline Yakhnat Mouloukhia & 4.2 & 2.5 & 1.3 & 0.4 & 5.4 & 12.5 & 2.9 & 3.2 & 0.1 & 0.5 & 0.3 & 0.1:0.5:1 \\
\hline
\end{tabular}

SFA: saturated fatty acids; MUFA: monounsaturated fatty acids; PUFA: polyunsaturated fatty acids; P:S: polyunsaturated fatty acids: saturated fatty acids ratio; M:S: monounsaturated fatty acids: saturated fatty acids ratio; P:M: polyunsaturated fatty acids: monounsaturated fatty acids ratio; P:M:S: polyunsaturated fatty acids: monounsaturated fatty acids: saturated fatty acids ratio.

Table 2. Fatty acid ratios and total fatty acid mean values in $100 \mathrm{~g}$ of edible portions of Arabic sweets and the percentage of their daily contribution in a 2000 kcal-diet.

\begin{tabular}{|c|c|c|c|c|c|c|c|c|c|c|c|c|}
\hline \multirow{2}{*}{ Arabic Sweet } & \multicolumn{4}{|c|}{$\begin{array}{c}\text { In } 100 \mathrm{~g} \text { of Edible Portions } \\
\text { (Per Gram) }\end{array}$} & \multicolumn{4}{|c|}{$\begin{array}{c}\text { Percentage of Daily } \\
\text { Contributions in } 2000 \text { Kcal-Diet }\end{array}$} & \multicolumn{4}{|c|}{ Fatty Acid Ratios } \\
\hline & Fat & SFA & MUFA & PUFA & Fat & SFA & MUFA & PUFA & $P: S$ & M:S & P:M & P:M:S \\
\hline Baklava mixed & 23.4 & 12 & 9.4 & 1.9 & 30 & 92.8 & 21.4 & 8.7 & 0.1 & 0.7 & 0.2 & $0.1: 0.7: 1$ \\
\hline Baklava mixed Light & 20.5 & 10.7 & 8.8 & 0.8 & 26.2 & 53.6 & 20.1 & 3.8 & 0 & 0.8 & 0 & $0: 0.8: 1$ \\
\hline Barazik & 25.3 & 12.1 & 10.3 & 2.8 & 32.4 & 60.5 & 23.4 & 13.1 & 0.2 & 0.8 & 0.2 & $0.2: 0.8: 1$ \\
\hline Boundoukia & 16.5 & 14.2 & 1.9 & 0.2 & 21.1 & 71.1 & 4.4 & 1.1 & 0 & 0.1 & 0.1 & $0: 0.1: 1$ \\
\hline Daoukia & 19.5 & 4.2 & 13.6 & 1.5 & 25 & 21.1 & 31 & 7 & 0.3 & 3.2 & 0.1 & $0.3: 3.2: 1$ \\
\hline Foustoukia & 14.8 & 10.4 & 4. & 0.2 & 18.9 & 52.1 & 9.2 & 1.1 & 0 & 0.3 & 0 & $0: 0.3: 1$ \\
\hline Ghourayba & 20.4 & 14 & 4 & 2.2 & 26.1 & 70.1 & 9 & 10.3 & 0.1 & 0.2 & 0.5 & $0.1: 0.2: 1$ \\
\hline Halawa & 25.8 & 16.1 & 7.9 & 1.5 & 33 & 80.6 & 18 & 7.1 & 0.1 & 0.4 & 0.2 & $0.1: 0.4: 1$ \\
\hline Halawa light & 25.5 & 12.6 & 12.2 & 0.5 & 32.6 & 63.1 & 27.8 & 2.3 & 0 & 0.9 & 0 & $0: 0.9: 0$ \\
\hline Halawat El Jiben & 8.9 & 7.2 & 1.3 & 0.2 & 11.4 & 55.8 & 3.1 & 0.9 & 0 & 0.1 & 0.1 & $0: 0.1: 1$ \\
\hline Ish el bulbul & 8.5 & 8.1 & 0.3 & 0 & 10.9 & 40.5 & 0.8 & 0.1 & 0 & 0 & 0.1 & $0: 0: 1$ \\
\hline kallaj kashta & 25.1 & 23.6 & 1.2 & 0.1 & 32.1 & 118.4 & 2.8 & 0.5 & 0 & 0 & 0.1 & $0: 0: 1$ \\
\hline karabij joz maa crema & 9.6 & 8.4 & 1 & 0.2 & 12.3 & 42 & 2.2 & 0.9 & 0 & 0.1 & 0.2 & $0: 0.1: 1$ \\
\hline Katayef Kashta & 6.6 & 4.3 & 1.9 & 0.3 & 8.5 & 33 & 4.4 & 1.5 & 0 & 0.4 & 0.1 & $0: 0.4: 1$ \\
\hline knefe kashta with kaak & 5.3 & 4.8 & 0.4 & 0 & 6.7 & 23.9 & 1 & 0.1 & 0 & 0 & 0 & $0: 0: 1$ \\
\hline Kounafa bil jiben & 12.2 & 11.1 & 0.9 & 0.1 & 15.7 & 85.3 & 2.2 & 0.4 & 0 & 0 & 0.1 & $0: 0: 1$ \\
\hline Maakroun & 12 & 9.4 & 2.2 & 0.3 & 15.3 & 72.3 & 5 & 1.5 & 0 & 0.2 & 0.1 & $0: 0.2: 1$ \\
\hline Maakroun wa mshabbak & 10.5 & 9 & 1.2 & 0.2 & 13.4 & 45.3 & 2.7 & 1 & 0 & 0.1 & 0.1 & $0: 0.1: 1$ \\
\hline Maamoul tamer & 17.4 & 11.5 & 5.2 & 0.5 & 22.3 & 88.4 & 11.8 & 2.6 & 0 & 0.4 & 0.1 & $0: 0.4: 1$ \\
\hline Maamoul mad kashta & 10.6 & 7.9 & 2.3 & 0.3 & 13.6 & 60.9 & 5.2 & 1.6 & 0 & 0.2 & 0.1 & $0: 0.2: 1$ \\
\hline Maamoul mad joz & 19.2 & 15.8 & 2.9 & 0.3 & 24.6 & 121.7 & 6.7 & 1.3 & 0 & 0.1 & 0.1 & $0: 0.1: 1$ \\
\hline Maamoul fostok & 14.4 & 12.2 & 2.1 & 0 & 18.4 & 60.9 & 4.8 & 0.3 & 0 & 0.1 & 0 & $0: 0.1: 1$ \\
\hline Maamoul joz & 21.5 & 12.1 & 6.8 & 2.3 & 27.5 & 93.1 & 15.6 & 10.5 & 0.1 & 0.5 & 0.3 & 0.1:0.5:1 \\
\hline Madlouka & 19.2 & 8.6 & 7 & 3.4 & 24.6 & 43.2 & 16.1 & 15.8 & 0.4 & 0.8 & 0.4 & $0.4: 0.8: 1$ \\
\hline Mafrouka kashta & 13.2 & 9.9 & 2.5 & 0.7 & 16.9 & 76.3 & 5.7 & 3.3 & 0 & 0.2 & 0.2 & $0: 0.2: 1$ \\
\hline Mafrouka fostok & 10.6 & 7.4 & 2.6 & 0.4 & 13.5 & 37.1 & 6.1 & 1.9 & 0 & 0.3 & 0.1 & $0: 0.3: 1$ \\
\hline Moushabak & 20.1 & 11.9 & 7.1 & 0.9 & 25.7 & 59.7 & 16.3 & 4.1 & 0 & 0.6 & 0.1 & $0: 0.6: 1$ \\
\hline Moufattaka & 13.1 & 12.6 & 0.3 & 0 & 16.7 & 63.2 & 0.7 & 0.3 & 0 & 0 & 0.2 & $0: 0: 1$ \\
\hline Mouhallabiya & 20.7 & 2.5 & 8.1 & 10 & 26.5 & 12.5 & 18.4 & 45.7 & 4 & 3.2 & 1.2 & $4: 3.2: 1$ \\
\hline Nammoura & 5.9 & 4 & 1.4 & 0.3 & 7.5 & 30.8 & 3.3 & 1.4 & 0 & 0.3 & 0.2 & $0: 0.3: 1$ \\
\hline Osmaliya & 16.2 & 14.3 & 1.4 & 0.3 & 20.8 & 110.6 & 3.2 & 1.5 & 0 & 0.1 & 0.2 & $0: 0.1: 1$ \\
\hline Riz bi halib & 9.5 & 7.3 & 1.5 & 0.5 & 12.1 & 36.9 & 3.5 & 2.3 & 0 & 0.2 & 0.3 & $0: 0.2: 1$ \\
\hline Saniora & 23.8 & 16.6 & 6.1 & 0.6 & 30.5 & 128.1 & 14 & 3.1 & 0 & 0.3 & 0.1 & $0: 0.3: 1$ \\
\hline Sfouf & 12.4 & 8.2 & 3.5 & 0.5 & 15.9 & 63.3 & 8 & 2.2 & 0 & 0.4 & 0.1 & $0: 0.4: 1$ \\
\hline Shaaybiyat & 11.6 & 7.4 & 3.5 & 0.4 & 14.8 & 37.3 & 8 & 2.1 & 0 & 0.4 & 0.1 & $0: 0.4: 1$ \\
\hline Ward el sham & 16.1 & 8.7 & 6 & 1.3 & 20.6 & 43.5 & 13.7 & 6 & 0.1 & 0.7 & 0.2 & 0.1:0.7:1 \\
\hline Znoud El sitt & 14.2 & 13 & 1 & 0 & 18.2 & 65.3 & 2.3 & 0 & 0 & 0 & 0 & $0: 0: 1$ \\
\hline
\end{tabular}

SFA: saturated fatty acids; MUFA: monounsaturated fatty acids; PUFA: polyunsaturated fatty acids; P:S: polyunsaturated fatty acids: saturated fatty acids ratio; M:S: monounsaturated fatty acids: saturated fatty acids ratio; P:M: polyunsaturated fatty acids: monounsaturated fatty acids ratio; P:M:S: polyunsaturated fatty acids: monounsaturated fatty acids: saturated fatty acids ratio. 
Table 3. Fatty acid ratios and total fatty acid content in $100 \mathrm{~g}$ of edible portions of market food products and the percentage of their daily contribution in a 2000 Kcal-diet.

\begin{tabular}{|c|c|c|c|c|c|c|c|c|c|c|c|c|c|}
\hline \multirow{2}{*}{$\begin{array}{l}\text { Food } \\
\text { Groups }\end{array}$} & \multirow{2}{*}{ Product } & \multicolumn{4}{|c|}{$\begin{array}{l}\text { In } 100 \mathrm{~g} \text { of Edible Portions } \\
\text { (Per Gram) }\end{array}$} & \multicolumn{4}{|c|}{$\begin{array}{c}\text { Daily Contributions in } 2000 \\
\text { Kcal-Diet }\end{array}$} & \multicolumn{4}{|c|}{ Fatty Acid Ratios } \\
\hline & & Fat & SFA & MUFA & PUFA & Fat & SFA & MUFA & PUFA & P:S & M:S & P:M & P:M:S \\
\hline \multirow{9}{*}{ Cereals } & \multirow{2}{*}{$\begin{array}{l}\text { Arabic Bread-White } \\
\text { Arabic Bread-Whole } \\
\text { wheat }\end{array}$} & 2.3 & 0.6 & 0.4 & 1.2 & 2.9 & 3.2 & 0.9 & 5.5 & 1.8 & 0.6 & 2.8 & 1.8:0.6:1 \\
\hline & & 4 & 1.3 & 0.5 & 2.1 & 5.1 & 6.9 & 1.1 & 9.6 & 1.5 & 0.3 & 4.2 & 1.5:0.3:1 \\
\hline & \multirow{3}{*}{$\begin{array}{c}\text { Baguette } \\
\text { Breakfast Cereals } \\
\text { Breakfast } \\
\text { Cereals-Chocolate }\end{array}$} & 0.5 & 0.1 & $\operatorname{Tr}$ & 0.2 & $\begin{array}{l}0.6 \\
26\end{array}$ & $\begin{array}{l}0.7 \\
48\end{array}$ & 0.1 & $\begin{array}{l}1.2 \\
1.4\end{array}$ & 1.7 & 0.4 & 4.3 & $\begin{array}{l}\text { 1.7:0.4:1 } \\
0.3: 0.8: 1\end{array}$ \\
\hline & & 2.1 & & 8 & & & & 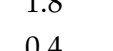 & 1.4 & & 8 & & $\begin{array}{l}0.3: 0.8: 1 \\
0 \cdot 0.1 \cdot 1\end{array}$ \\
\hline & & 2.4 & 2.1 & 0.2 & Ir & 3 & 10.5 & 0.4 & 0.3 & 0 & 0.1 & 0.4 & 0:0.1:1 \\
\hline & $\begin{array}{l}\text { Croissant Zaatar-1 } \\
\text { Croissant zaatar-2 }\end{array}$ & $\begin{array}{l}16.1 \\
22.5\end{array}$ & $\begin{array}{l}15.1 \\
15.1\end{array}$ & $\begin{array}{l}0.8 \\
5.4\end{array}$ & $\begin{array}{l}0.1 \\
1.7\end{array}$ & $\begin{array}{l}20.6 \\
28.8\end{array}$ & $\begin{array}{l}75.9 \\
75.7\end{array}$ & $\begin{array}{c}1.8 \\
12.4\end{array}$ & $\begin{array}{l}0.4 \\
7.7\end{array}$ & $\begin{array}{c}0 \\
0.1\end{array}$ & $\begin{array}{c}0 \\
0.3\end{array}$ & $\begin{array}{l}0.1 \\
0.3\end{array}$ & $\begin{array}{c}0: 0: 1 \\
0.1: 0.3: 1\end{array}$ \\
\hline & Kaak Asrouni & 1.5 & 0.2 & 0.5 & 0.7 & 1.9 & 1.1 & 1.1 & 3.4 & 3.2 & 2.1 & 1.5 & $3.2: 2.1: 1$ \\
\hline & Kaak Debes and Cacao & 11.9 & 5.5 & 4.9 & 1.3 & 15.2 & 27.9 & 11.2 & 6 & 0.2 & 0.8 & 0.2 & $0.2: 0.8: 1$ \\
\hline & Kaak Korshalli & 6.9 & 3.1 & 2.4 & 1.3 & 8.8 & 15.6 & 5.5 & 5.9 & 0.4 & 0.7 & 0.5 & 0.4:0.7:1 \\
\hline \multirow{7}{*}{$\begin{array}{l}\text { Oil } \\
\text { and } \\
\text { fats }\end{array}$} & Butter & 81.4 & 56.4 & 23 & 1.4 & 104.3 & 282 & 52.3 & 6.6 & 0 & 0.4 & 0 & $0: 0.4: 1$ \\
\hline & Butter Light & 61.5 & 43.4 & 16.4 & 1.1 & 78.8 & 217.4 & 37.3 & 5 & 0 & 0.3 & 0 & $0: 0.3: 1$ \\
\hline & Corn Oil & 100 & 10.3 & 31 & 58.7 & 128.2 & 51.5 & 70.4 & 266.8 & 5.7 & 3 & 1.8 & $5.7: 3: 1$ \\
\hline & Olive Oil & 100 & 14.9 & 74.3 & 10.8 & 128.2 & 74.5 & 168.8 & 49 & 0.7 & 4.9 & 0.1 & 0.7:4.9:1 \\
\hline & Sunflower Oil & 100 & 7.6 & 29.8 & 62.6 & 128.2 & 38 & 67.7 & 284.5 & 8.2 & 3.9 & 2.1 & 8.2:3.9:1 \\
\hline & Tahina & 59.4 & 17.1 & 30 & 12.2 & 76.1 & 85.5 & 68.1 & 55.6 & 0.7 & 1.7 & 0.4 & 0.7:1.7:1 \\
\hline & Vegetable Margarine & 99 & 46.7 & 27.4 & 24.8 & 126.9 & 233.6 & 62.3 & 112.9 & 0.5 & 0.5 & 0.9 & $0.5: 0.5: 1$ \\
\hline \multirow{15}{*}{ Sugar } & \multirow{3}{*}{$\begin{array}{c}\text { Biscuits Chocolate } \\
\text { Quinoa } \\
\text { Biscuits Digestive } \\
\text { Biscuits Digestive } \\
\text { Light }\end{array}$} & 13.4 & 1.8 & 9.6 & 1.9 & 17.1 & 8.9 & 21.9 & 8.7 & 1 & 5.3 & 0.2 & $1: 5.3: 1$ \\
\hline & & 17.1 & 15.6 & 1 & 0.3 & 21.9 & 78.2 & 2.3 & 1.7 & 0 & 0 & 0.3 & $0: 0: 1$ \\
\hline & & 13.8 & 12.2 & 0.7 & 0.7 & 17.6 & 61 & 1.7 & 3.5 & 0 & 0 & 1 & $0: 0: 1$ \\
\hline & Biscuits with cream & 15.5 & 7.8 & 6 & 1.6 & 19.8 & 39 & 13.6 & 7.6 & 0.2 & 0.7 & 0.2 & $0.2: 0.7: 1$ \\
\hline & Chocolate Dark & 33.6 & 33.1 & 0.4 & $\operatorname{Tr}$ & 43 & 165.6 & 0.9 & 0.1 & 0 & 0 & 0 & 0:0:1.0 \\
\hline & Chocolate Milk-1 & 36.6 & 36.1 & 0.4 & $\operatorname{Tr}$ & 46.9 & 180.6 & 1 & $\operatorname{Tr}$ & $\operatorname{Tr}$ & 0 & $\operatorname{Tr}$ & $0: 0: 1.0$ \\
\hline & Chocolate Milk-2 & 35 & 34.7 & 0.2 & $\operatorname{Tr}$ & 44.8 & 173.6 & 0.5 & 0.1 & 0 & 0 & 0.1 & 0:0:1.0 \\
\hline & Doughnuts & 19.6 & 12.8 & 6 & 0.6 & 25. & 64.3 & 13.6 & 2.7 & 0 & 0.4 & 0.1 & $0: 0.4: 1$ \\
\hline & $\begin{array}{c}\text { English } \\
\text { Cake-Chocolate }\end{array}$ & 18.6 & 9.17 & 6.4 & 2.4 & 23.8 & 45.8 & 14.7 & 11.1 & 0.2 & 0.7 & 0.3 & $0.2: 0.7: 1$ \\
\hline & Cake with Cream & 16.1 & 14.2 & 1.4 & 0.3 & 20.6 & 71.3 & 3.3 & 1.6 & 0. & 0.1 & 0.2 & $0: 0.1: 1$ \\
\hline & Pain au Lait & 3.8 & 1.9 & & 0.8 & 4.8 & 9.8 & 2 & 3.7 & 0.4 & 0.4 & 0.9 & $0.4: 0.4: 1$ \\
\hline & Petit $\mathrm{F}$ & 25.6 & 15.9 & 8.4 & 1.2 & 32 & 79.4 & 19 & 5.7 & 0 & 0.5 & 0.1 & $0: 0.5: 1$ \\
\hline & Petit F & 29.6 & 26.7 & & 0.1 & 37 & 133.9 & 5. & 0.5 & 0 & 0.1 & 0 & $0: 0.1: 1$ \\
\hline & Wafer-Chocolate-1 & 21.7 & 19.6 & 1.4 & 0.5 & 27. & 98.4 & 3. & 2.6 & 0 & 0 & 0.4 & $0: 0: 1$ \\
\hline & Wafer-Chocolate-2 & 24.2 & 19.1 & 2.4 & 1 & 31 & 95.5 & 5.5 & 4.8 & 0 & 0.1 & 0.4 & $0: 0.1: 1$ \\
\hline \multirow{4}{*}{ Drinks } & Coffee with cardamom & 16.8 & 14 & 2.1 & 0.5 & 21.5 & 70.3 & 4.7 & 2.6 & 0 & 0.1 & 0.2 & $0: 0.1: 1$ \\
\hline & $\begin{array}{l}\text { Coffee without } \\
\text { cardamom }\end{array}$ & 17.7 & 12.9 & 2.5 & 2.1 & 22.6 & 64.6 & 5.8 & 9.8 & 0.1 & 0.2 & 0.8 & 0.1:0.2:1 \\
\hline & Hot Chocolate Powder & 5.4 & 3.5 & 1.7 & 0.1 & 6.9 & 17.5 & 3.8 & 0.8 & 0 & 0.4 & 0.1 & $0: 0.4: 1$ \\
\hline & Instant Coffee & 10.8 & 10.6 & 0.1 & $\operatorname{Tr}$ & 13.8 & 53.3 & 0.2 & 0.1 & 0 & 0 & 0.2 & $0: 0: 1$ \\
\hline \multirow{4}{*}{$\begin{array}{l}\text { Nuts } \\
\text { and } \\
\text { seeds }\end{array}$} & $\begin{array}{c}\text { De-hulled } \\
\text { pumpkin seeds }\end{array}$ & 50.6 & 34 & 15.4 & 0.8 & 64.8 & 170.2 & 35 & 3.6 & 0 & 0.4 & 0 & $0: 0.4: 1$ \\
\hline & $\begin{array}{l}\text { De-hulled } \\
\text { sunflower seeds }\end{array}$ & 52.5 & 26.7 & 19.1 & 6.3 & 67.3 & 133.6 & 43.4 & 28.6 & 0.2 & 0.7 & 0.3 & $0.2: 0.7: 1$ \\
\hline & Mixed Nuts & 25.7 & 13.1 & 10.1 & 2.3 & 32.9 & 65.9 & 23 & 10.5 & 0.1 & 0.7 & 0.2 & 0.1:0.7:1 \\
\hline & Mixed Kernels & 53.6 & 10.9 & 39.4 & 3.1 & 68.7 & 54.9 & 89.6 & 14.3 & 0.2 & 3.5 & 0 & $0.2: 3.5: 1$ \\
\hline \multirow{4}{*}{ Snacks } & Potato Chips-1 & 29.9 & 20.2 & 9.5 & 0.1 & 38.3 & 101.2 & 21.6 & 0.5 & 0 & 0.4 & 0 & $0: 0.4: 1$ \\
\hline & Potato Chips-2 & 15.4 & & 7.9 & 0.9 & 19.7 & 32.4 & 17. & 4.3 & 0.1 & 1.2 & 0.1 & 0.1:1.2:1 \\
\hline & Potato Chips Light-1 & 26.9 & 18.3 & 8.4 & $\operatorname{Tr}$ & 34.4 & 91.8 & 19.2 & 0.2 & 0 & 0.4 & 0 & $0: 0.4: 1$ \\
\hline & Potato Chips Light-2 & 22.9 & 15 & 6.9 & 0.8 & 29.3 & 75.2 & 15.8 & 3.7 & 0 & 0.4 & 0.1 & $0: 0.4: 1$ \\
\hline \multirow{2}{*}{ Canned } & Tuna Packed in Oil & 6.8 & 3.2 & 2 & 1.4 & 8.7 & 16.3 & 4.6 & 6.6 & 0.4 & 0.6 & 0.7 & 0.4:0.6:1 \\
\hline & Tuna Packed in Water & 0.5 & 0.2 & 0.2 & $\mathrm{Tr}$ & 0.6 & 1.2 & 0.5 & 0.1 & 0.1 & 0.9 & 0.1 & $0.1: 0.9:$ \\
\hline
\end{tabular}

SFA: saturated fatty acids; MUFA: monounsaturated fatty acids; PUFA: polyunsaturated fatty acids; P:S: polyunsaturated fatty acids: saturated fatty acids ratio; M:S: monounsaturated fatty acids: saturated fatty acids ratio; P:M: polyunsaturated fatty acids: monounsaturated fatty acids ratio; P:M:S: polyunsaturated fatty acids: monounsaturated fatty acids: saturated fatty acids ratio.

The full methodology of food list identifications and food sampling is described elsewhere $[16,17]$. 


\subsection{Chemical Analysis}

Around $500 \mathrm{~g}$ of each sample was mashed, then analyzed, and the remaining samples were kept frozen at $-18{ }^{\circ} \mathrm{C}$ for further analysis. The fatty acid profile was measured using gas chromatography. Each analysis method was selected considering guidance from the technical committee at the Industrial Research Institute laboratories in Beirut and following standardized protocols. The Association of Official Analytical Chemists (AOAC) methods were used for analysis of nutrients in food matrices [18].

Soxhlet extraction (Total fatty acids extraction):

The Roese-Gotlieb method was used in the investigation of the fat content (AOAC $945.48,933.05 \& 963.15,2019)$. Between $1-2 \mathrm{~g}$ of the dried food sample was filtered using a piece of filter paper. Later, it was wrapped and introduced into the soxhlet thimble. To avoid sample spilling, a cotton plug was placed at the top of the thimble. The soxhlet apparatus was assembled and a light petroleum, hexane, heptane, diethyl ether, or cyclohexane was used. The extraction was performed overnight. If solids from the thimble or sample were found in the solvent extract, a filtration before evaporation into another tarred flask or beaker was performed. Then it was dried to a constant weight, which was attained when successive $1 \mathrm{~h}$ drying periods showed additional loss of less than 0.05 fat. The percentage $(\%)$ fat was equal to $(\mathrm{g})$ fat $\times 100 \mathrm{~g}$ sample.

Fatty Acid Profile (saturated, unsaturated, trans):

The extracted fat of the sample that was obtained during fat determination was used to analyze the fatty acid profile. Between $200-500 \mathrm{mg}$ of the lipid sample was placed in a boiling flask with chips; then, $5 \mathrm{~mL}$ of $0.5 \mathrm{M}$ methanolic $\mathrm{KOH}$ was added. Esterification was performed by boiling under reflux for 3-5 min. An addition of $15 \mathrm{~mL}$ of esterification reagent $\left(2 \mathrm{~g} \mathrm{NaNH}_{4}+60 \mathrm{~mL}\right.$ methanol $+3 \mathrm{~mL}$ conc sulfuric acid) through the condenser was performed, and then the sample was boiled for $15 \mathrm{~min}$. After cooling, there was an addition of $50 \mathrm{~mL}$ of distilled water and $25 \mathrm{~mL}$ of the solvent. The organic layer was isolated by means of a separatory funnel. Finally, the solvent layer was washed twice with distilled water.

Chromatographic analysis:

Column: fatty acid methyl esters (FAME) length: $30 \mathrm{~m}, 0.32$ ID

Injection volume: $1 \mu \mathrm{L}$

Injector temperature (PTV): injection: $60^{\circ} \mathrm{C}$ for $0.1 \mathrm{~min}$

Transfer: ramp $10{ }^{\circ} \mathrm{C} / \mathrm{min}$ to $270{ }^{\circ} \mathrm{C}, 1 \mathrm{~min}$ hold

Carrier flow (He): $2.0 \mathrm{~mL} / \mathrm{min}$

Split flow: $20 \mathrm{~mL} / \mathrm{min}$ (split ratio: 20 )

Detector temperature (flame ionization detection (FID)) $280^{\circ} \mathrm{C}$

Detector gases flows: Air $350 \mathrm{~mL} / \mathrm{min}$, Hydrogen $32 \mathrm{~mL} / \mathrm{min}$, Make-up $\left(\mathrm{N}_{2}\right) 30 \mathrm{~mL} / \mathrm{min}$

Oven Program:

Initial temperature: $100{ }^{\circ} \mathrm{C}$, hold $3 \mathrm{~min}$

-Ramp 1: $10^{\circ} \mathrm{C} / \mathrm{min}$ to $200^{\circ} \mathrm{C}$, hold $3 \mathrm{~min}$

-Ramp 2: $10^{\circ} \mathrm{C} / \mathrm{min}$ to $250^{\circ} \mathrm{C}$, hold $5 \mathrm{~min}$

Using the chromatograph software, an integration of the areas under the peak was detected under the standards peaks. A calculation as percentage areas was done.

The sum of SFA, MUFA, and PUFA, as well as the sum of trans fatty acids, was calculated accordingly (ISO 12966-4, AOAC 985.21, 2019).

\subsection{Fatty Acids Ratios}

The polyunsaturated:saturated (P:S) fatty acids ratio is frequently used as an indicator of the quality of fat in the diet. The United State (U.S.) National Research Council recommends a P:S ratio of 1:1. Furthermore, the U.S. Senate Select Committee recommended a ratio of 1:1:1 of PUFA, MUFA, and SFA (P:M:S) in the dietary fat intake in the United States [19]. Since these dishes constitute the major food items in lunches and dinners, both the P:S and P:M:S ratios were calculated and are presented in Tables 1-3. Additional 
calculations of M:S and P:M ratios are presented in the same tables, but are not discussed in this article.

\subsection{Contributions to Daily Values}

The daily value (DV) is defined by the US Food and Drug Administration (FDA) as the following: "reference values for reporting nutrients on the nutrition labels". Moreover, the percentage (\%) of DV assists the consumer in recognizing whether the serving of food and its content in nutrients is high $(>20 \%)$, good $(10-19 \%)$, or low $(<10 \%)[17,20]$. According to the "Healthy Diet report" published by the World Health Organization [21], in a total daily calorie intake of $2000 \mathrm{Kcal}$, the total fatty acids, MUFA, PUFA and SFA daily intake should constitute $35 \%, 20 \%, 10 \%$ and up to $9 \%$, respectively. In term of grams per day $(\mathrm{g} / \mathrm{d})$, these percentages are equivalent to $78 \mathrm{~g} / \mathrm{d}, 44 \mathrm{~g} / \mathrm{d}, 22 \mathrm{~g} / \mathrm{d}$ and $20 \mathrm{~g} / \mathrm{d}$, respectively. Referring to the dishes and food items selected in our study, the required amount per day of total, unsaturated, and saturated fatty acid was calculated. The calculations are displayed in Tables 1-3.

\section{Results and Discussion}

The results of the fatty acids profile, DVs and ratios of the Lebanese composite dishes, Arabic sweets and market products are presented in Tables 1-3.

\subsection{Total Fatty Acids}

The range of total fatty acids in composite dishes, Arabic sweets, and market food products was between $1.2-11.7 \mathrm{~g} / 100 \mathrm{~g}, 5.3-25.8 \mathrm{~g} / 100 \mathrm{~g}$, and $0.5-100 \mathrm{~g} / 100 \mathrm{~g}$, respectively. Around only $16 \%$ of traditional dishes samples contained an amount of total fatty acids that exceeded the $10 \%$ of DV. The highest mean value of total fatty acids was observed in Shawarma Lahma and Falafel (Table 1). Other dishes had variable content of total fatty acids that depended on the fat source in each recipe. According to literature and in terms of Falafel, our results went hand-in-hand with those of Bawadi \& Al-Sahawneh in Jordan [22] and Al Faris in Saudi Arabia [23] (Table 4). As for fatayer sabanikh, in our results, the total fatty acids were much higher than that reported in Lebanon in 1970 [24] in Jordan [22], in Saudi Arabia [23] and in Bahrain [25,26] (Table 4). Furthermore, hindbe bil zeit and lahm bil ajin showed that the first dish contained 1.5 times more and the second dish contained 5 times less total fatty acids compared to 1970, respectively [24]. The type of frying oil, the fatness of meat and the cooking method of the composite dishes all together could play a major role in the variability of our results.

Regarding the Arabic sweet samples, around $48 \%$ of the samples contained a high amount of total fatty acids in which their contributions to the DV exceeded $20 \%$. The highest mean value of total fatty acids was observed in halawa (25.8 g/100 g) (Table 2). Also, a high content of total fatty acids was detected in halawa light $(25.5 \mathrm{~g} / 100 \mathrm{~g})$, barazik (25.3 g/100 g), kallaj kashta $(25.1 \mathrm{~g} / 100 \mathrm{~g})$, saniora $(23.8 \mathrm{~g} / 100 \mathrm{~g})$, baklava mixed (23.4 g/100 g), baklava mixed light (20.5 g/100 g), ghourayba (20.4 g/100 g), and moushabak $(20.1 \mathrm{~g} / 100 \mathrm{~g})$ (Table 2). Referring to the literature, and comparing with our results, the total fatty acids in baklava mixed was much lower than that reported in Jordan [22], and in Bahrain $[25,26]$ (Table 4). Similarly, for barazik and ghourayba, their content in total fatty acids was lower that reported in Jordan [22] (Table 5). However, our results for kallaj kashta go with the results of Bawadi \& Al-Sahawneh in Jordan [22] (Table 4).

As for the market foods, the total fatty acid content ranged between $0.5 \mathrm{~g}$ and up to $100 \mathrm{~g}$ in $100 \mathrm{~g}$ of the analyzed market foods. The lowest total fatty acid content was observed in the baguette and tuna packed in water $(0.5 \mathrm{~g} / 100 \mathrm{~g})$ while the highest content was observed in corn oil, olive oil, and sunflower oil (100 g/100 g) (Table 3). 
Table 4. List of fat composition of food commonly tested in Lebanon, Kuwait, Jordan, Saudi Arabia, and Bahrain [22-27].

\begin{tabular}{|c|c|c|c|c|c|c|c|}
\hline $\begin{array}{l}\text { Comparison with } \\
\text { EM Countries }\end{array}$ & [24] & [25] & $\begin{array}{c}\text { Lebanon } \\
2020\end{array}$ & [27] & [22] & [23] & [26] \\
\hline Dishes Names & Fat in $100 \mathrm{~g}$ & Fat in $100 \mathrm{~g}$ & Fat in $100 \mathrm{~g}$ & Fat in $100 \mathrm{~g}$ & Fat in $100 \mathrm{~g}$ & Fat in $100 \mathrm{~g}$ & Fat in $100 \mathrm{~g}$ \\
\hline Baba ghanouj & 3.7 & NA * & 9.44 & 8.7 & 5.4 & NA & NA \\
\hline Batata mahshi & 5.6 & NA & 1.24 & NA & NA & 5.9 & NA \\
\hline Bourghol bil banadoura & NA & 10.16 & 5.02 & NA & NA & NA & NA \\
\hline Chichbarak & NA & 8.89 & 4.6 & NA & NA & NA & NA \\
\hline Falafel & NA & NA & 11.7 & NA & 18.4 & 14.3 & NA \\
\hline Fatayir sabanekh & 6.6 & NA & 11 & 6.12 & 7.6 & 2.75 & 7 \\
\hline Fattoush & 6.3 & NA & 2.94 & 2.17 & 8.6 & NA & NA \\
\hline Foul moudamas & 3.1 & NA & 3.48 & 3.15 & 7.3 & 3.2 & NA \\
\hline Hindbe bil zeit & 6.7 & NA & 10.7 & NA & NA & NA & NA \\
\hline Hommus bil tahina & 19.7 & NA & 6.4 & 7.7 & NA & 17.8 & NA \\
\hline Mosakaa batinjen & NA & NA & 6.58 & NA & NA & 16.4 & NA \\
\hline Kafta (only) & 22.1 & NA & 6.32 & NA & NA & NA & NA \\
\hline Kussa mahshi & 1.7 & NA & 2.42 & NA & NA & NA & NA \\
\hline Lahm bil ajin & 39.5 & NA & 8 & NA & NA & NA & NA \\
\hline Malfuf mahshi & 2.6 & NA & 2.12 & NA & NA & NA & NA \\
\hline Moujadara & 5.6 & NA & 5.8 & NA & NA & NA & NA \\
\hline Riz a dajaj & 9.3 & NA & 5.4 & NA & NA & NA & NA \\
\hline Sayadiya & 13.2 & NA & 6.48 & $\begin{array}{c}3.98 \\
\text { (sandwich) }\end{array}$ & NA & NA & NA \\
\hline Shawarma dajaj & NA & NA & 6.94 & $\begin{array}{c}3.90 \\
\text { (sandwich) }\end{array}$ & NA & NA & 11.2 \\
\hline Shawarma Lahma & 36 & NA & 8.28 & NA & 14 & NA & 9.4 \\
\hline Tabbouli & 5.8 & NA & 4.24 & 3.3 & 2.6 & NA & NA \\
\hline Warak enab mahshi & 7.3 & NA & 3.98 & NA & NA & 3.7 & NA \\
\hline Yakhnat bamyah & 7.2 & 11.09 & 5.4 & NA & NA & NA & NA \\
\hline Yakhnat Fassoulia & 6.6 & NA & 3.9 & NA & NA & NA & NA \\
\hline Yakhnat mulukhiya & 6.4 & NA & 4.28 & NA & NA & 0.25 & NA \\
\hline Baklava mixed & NA & NA & 27.3 & NA & 28.7 & NA & 38.8 \\
\hline Barazik & NA & NA & 42.1 & NA & 31.6 & NA & NA \\
\hline Ghouraybah & 21.3 & NA & 32.9 & NA & 28 & NA & NA \\
\hline Kallaj kashta & NA & NA & 9.7 & NA & 25.8 & NA & NA \\
\hline Katayef kashta & NA & NA & 10.5 & NA & 7.1 & NA & NA \\
\hline Knefah bil jibn & NA & NA & 13.2 & NA & 21.6 & NA & NA \\
\hline $\begin{array}{l}\text { Maakroun and } \\
\text { Moushabak }\end{array}$ & 17.2 & NA & 17.9 & NA & NA & NA & NA \\
\hline Maamoul tamer & 9 & NA & 15.6 & NA & 16.3 & NA & NA \\
\hline Maamoul fostok & NA & NA & 26.9 & NA & 19.3 & NA & NA \\
\hline Maamoul joz & NA & NA & 18.3 & NA & 27.3 & NA & NA \\
\hline Nammoura & 3.1 & NA & 8.8 & NA & 18.4 & NA & $\mathrm{NA}$ \\
\hline
\end{tabular}

* NA: Not available.

Table 5. Comparison between actual nutrient analysis values of market food products and reported nutrient values on nutrition fact label.

\begin{tabular}{|c|c|c|c|c|c|c|c|c|}
\hline \multirow{2}{*}{ Product } & \multicolumn{2}{|c|}{ Fat } & \multicolumn{2}{|c|}{ SFA } & \multicolumn{2}{|c|}{ MUFA } & \multicolumn{2}{|c|}{ PUFA } \\
\hline & Chem-R * & N.label $^{\wedge}$ & Chem-R & N.label & Chem-R & N.label & Chem-R & N.label \\
\hline Biscuits Chocolate Quinoa & 13.4 & 5 & 1.8 & $\mathrm{Tr}$ & 9.6 & NA & 1.9 & NA \\
\hline Biscuits Digestive & 17.1 & 26 & 15.6 & 15 & 1 & NA & 0.3 & NA \\
\hline Biscuits Digestive Light & 13.8 & 13.5 & 12.2 & 13.5 & 0.7 & NA & 0.7 & NA \\
\hline Breakfast Cereals & 2.1 & 0.4 & 0.9 & 0.1 & 0.8 & 0.1 & 0.3 & 0.2 \\
\hline Breakfast Cereals-Chocolate & 2.4 & 5.2 & 2.1 & 5.2 & 0.2 & NA & 0 & NA \\
\hline Butter & 81.4 & 80 & 56.4 & 54 & 23 & NA & 1.4 & NA \\
\hline Butter Light & 61.5 & 20 & 43.4 & 53.3 & 16.4 & NA & 1.1 & NA \\
\hline Chocolate Wafers & 21.7 & 25 & 19.6 & 21 & 1.4 & NA & 0.5 & NA \\
\hline Chocolate wafers-brand 2 & 24.2 & 27.27 & 19.1 & 9 & 2.4 & NA & 1 & NA \\
\hline Chocolate with milk & 36.6 & 73 & 36.1 & 46 & 0.4 & NA & $\operatorname{Tr}$ & NA \\
\hline Chocolate-Dark & 33.6 & 40 & 33.1 & 23.3 & 0.4 & NA & $\operatorname{Tr}$ & NA \\
\hline Chocolate-White & 35 & NA & 34.7 & NA & 0.2 & NA & $\mathrm{Tr}$ & NA \\
\hline Corn Oil & 100 & 100 & 10.3 & 14 & 31 & 24 & 58.7 & 61 \\
\hline Cream Filled Biscuits & 15.5 & 18.6 & 7.8 & 4.6 & 6 & NA & 1.6 & NA \\
\hline Hot Chocolate Powder & 5.4 & 5.9 & 3.5 & 3.7 & 1.7 & NA & 0.1 & NA \\
\hline
\end{tabular}


Table 5. Cont.

\begin{tabular}{|c|c|c|c|c|c|c|c|c|}
\hline \multirow{2}{*}{ Product } & \multicolumn{2}{|c|}{ Fat } & \multicolumn{2}{|c|}{ SFA } & \multicolumn{2}{|c|}{ MUFA } & \multicolumn{2}{|c|}{ PUFA } \\
\hline & Chem-R * & N.label ^ & Chem-R & N.label & Chem-R & N.label & Chem-R & N.label \\
\hline Instant Coffee ( 3 in 1$)$ & 10.8 & 9.09 & 10.6 & 9 & 0.1 & NA & 0 & NA \\
\hline Chips Baked & 22.9 & 22 & 15 & 6 & 6.9 & NA & 0.8 & NA \\
\hline Lays Chips Cheese & 15.4 & 12 & 6.5 & 3 & 7.9 & NA & 0.9 & NA \\
\hline Olive Oil & 100 & 100 & 14.9 & 24 & 74.3 & 87 & 10.8 & 22 \\
\hline Potato Chips & 29.9 & 26.6 & 20.2 & 10 & 9.5 & 10 & 0.1 & 3.3 \\
\hline Potato Chips Light & 26.9 & 20 & 18.3 & 6.6 & 8.4 & 6.6 & $\mathrm{Tr}$ & NA \\
\hline Sunflower Oil & 100 & 100 & 7.6 & 10 & 29.8 & 20 & 62.6 & 60 \\
\hline Tahina & 59.4 & 60 & 17.1 & 10 & 30 & NA & 12.2 & NA \\
\hline Tuna Packed in Oil & 6.8 & 26.6 & 3.2 & NA & 2 & NA & 1.4 & NA \\
\hline Tuna Packed in Water & 0.5 & 3 & 0.2 & NA & 0.2 & NA & $\mathrm{Tr}$ & NA \\
\hline Vegetable Margarine & $>99$ & 56.4 & 46.7 & 9.5 & 27.4 & 19 & 24.8 & 23 \\
\hline
\end{tabular}

* Chemical results, ^ nutrition facts label, NA: not available, Tr: trace, SFA: saturated fatty acids; MUFA: monounsaturated fatty acids; PUFA: polyunsaturated fatty acids.

\subsection{Saturated Fat}

The highest mean values of SFA were present in Shawarma lahma (Table 1). As for the Arabic sweets, the highest mean values of SFA were observed in kallaj kashta (23.6 g/100 g), saniora (16.6 g/100 g), and maamoul mad joz (15.8 g/100 g) (Table 2). The SFA content varied across market foods ranging between $0.5 \%$ to more than $50 \%(0.1$ and $56.4 \mathrm{~g} / 100 \mathrm{~g}$ in the baguette and butter respectively). In addition, half the foods had a \% DV higher than $20 \%$ except for tuna packed in oil and water and some baked goods (Table 3 ).

\subsection{Monounsaturated Fatty Acid}

The highest mean value of MUFA was observed in hindbe bil zeit (6.3\%) (Table 1). Half the traditional dish samples met less than $5 \%$ of the DV for MUFA and as such were considered poor sources of MUFA (Table 1). Additionally, the highest mean value of MUFA among the Arabic sweets was seen in daoukia (13.6 g/100 g) (Table 2). However, the MUFA contribution was less than $14 \%$ in the majority of the Arabic sweets. Similarly, almost all market products contained trace amounts of MUFA except for olive oil (74.3 g/100 g) (Table 3).

\subsection{Polyunsaturated Fatty Acid}

Fatayer sabanikh had the highest mean value of PUFA across the Lebanese governorates (Table 1). Only three traditional dishes out of 30 met more than $20 \%$ DV for PUFA; therefore, the majority of these foods were considered poor sources of PUFA (Table 1). The highest mean value of PUFA was seen in madlouka which contains $3.4 \mathrm{~g} / 100 \mathrm{~g}$ (Table 2). The majority of the Arabic sweets presented a poor PUFA content. Also, almost all market products contained trace amounts of PUFA except for sunflower Oil (62.6 g/100 g) (Table 3).

According to Brouwer (2016), an amelioration in the lipoprotein profile could be observed when substituting SFA in the diet with PUFA; this same effect was seen slightly with MUFA [28]. According to Zong, et al., MUFA affects serum lipid levels and induces benefits at the heart level [29]. The poorness in MUFA and PUFA of the majority of traditional dishes, Arabic sweets and market food in Lebanon is an alarming issue that need to be studied in light of the rise of NCDs, which are responsible of $91 \%$ of deaths in Lebanon [30].

\subsection{Fatty Acids Ratios}

\subsubsection{Polyunsaturated Fatty Acid: Saturated Fatty Acid Ratio (P:S)}

Fatayer sabanikh was seen to have the most elevated mean value of P:S ratio (Table 1), whereas the P:S ratio of all the meals was far from 1:1, indicating a low-fat quality diet. This may be due to the heavy usage of animal fat sources in foods instead of using vegetable oils, and it highlights the need for national food preparation adjustments. Furthermore, almost 
all Arabic sweets have shown a deviation of P:S ratio from 1:1 (Table 2). Furthermore, the P:S ratio in all the market foods was also deviating from 1:1 (Table 3).

\subsubsection{Polyunsaturated Fatty Acid: Monounsaturated Fatty Acid: Saturated Fatty Acid Ratio (P:M:S)}

The P:M:S across all food samples from the different governorates deviated from the recommended 1:1:1 ratio. Also, a deviation of the P:M:S ratio from 1:1:1 was seen among all Arabic sweets (Table 2), as well as among all market foods (Table 3).

These findings further highlight the need to modify traditional dishes in terms of fatty acids to achieve a more calibrated P:M:S ratio. This deviation could lead to an inverse relationship between the unsaturated fatty acids levels in food and coronary heart diseases [28]. A deviated P:M:S ratio can raise serum cholesterol and impact heart disease risk markers [31]. The deviated ratio in our study went hand in hand with Sawaya, et al. in Kuwait [32].

\subsection{Comparison Between Market Foods: Nutrient Content Versus Nutrition Fact Label}

All products were found to have discrepancies in reporting the actual nutrient content when compared to their respective nutrition facts label (Table 5). For instance, the butter light had a difference between the analyzed nutrition $(61.5 \mathrm{~g} / 100 \mathrm{~g})$ and the labelled nutrition $(20 \mathrm{~g} / 100 \mathrm{~g})$. Some products such as sunflower oil and olive oil had matching values for fatty acid content. As for the saturated fatty acid content, there was a discrepancy between the nutrition label and nutrient content of the chocolate wafers-brand $2(19.1 \mathrm{~g} / 100 \mathrm{~g}$ and $9 \mathrm{~g} / 100 \mathrm{~g}$ ), chocolate with milk ( $36.1 \mathrm{~g} / 100 \mathrm{~g}$ and $46 \mathrm{~g} / 100 \mathrm{~g}$ ), chocolate-dark (33.1 g/100 g and $23.3 \mathrm{~g} / 100 \mathrm{~g})$, potato chips $(20.2 \mathrm{~g} / 100 \mathrm{~g}$ and $10 \mathrm{~g} / 100 \mathrm{~g})$ and butter light $(43.4 \mathrm{~g} / 100 \mathrm{~g}$ and $53.3 \mathrm{~g} / 100 \mathrm{~g}$ ). Nonetheless, there were analyzed values double or more than that of the labelled in products including Lays chips cheese and potato chips light (Table 5).

While MUFA and PUFA were rarely reported on the nutrition facts label, analysis of the market food products revealed trace amounts as mentioned earlier. In terms of promoting healthy behaviors and food choices, not only the nutritional quantity of food consumed, but also the quality of ingredients including the lipid profile, needs to be considered, because according to a recent systematic review, there is an impact of food labels on food choices and healthiness attitudes and practices among consumers [33].

There is a gap in the data on food consumption patterns among Lebanese populations and this should be identified and quantified by means of individual dietary surveys, without which the dietary intake of fatty acid cannot be estimated. Nowadays, such an approach is a challenge in LMICs, which are grasping the nettle of infectious diseases and epidemic outbreaks (such as Ebola and COVID-19), removing the focus from acute and chronic care of NCDs. Thus, long-term care for NCDs would assist in making the health systems ready to walk side by side with other acute diseases. The implementation of such a system will require fund allocations at both the national and international level. Moreover, this achievement should align the NCD agenda, taking into consideration national and international efforts to implement accessible and equitable health promotion systems in order to fortify capacity building and prioritize the achievement of NCD-focused health systems.

\section{Conclusions}

For the first time, this study shows that the majority of the frequently consumed traditional dishes in Lebanon have a deviated P:M:S ratio reflecting an alarming impact on coronary health of the Lebanese population and ringing the alarm bell regarding the priority of controlling the quality of Lebanese diet in terms of fatty acids. The results of this study recommend that, although cultural heritage is encouraged by consuming traditional dishes, a healthier choice of ingredients will go a long way in preventing non-communicable diseases associated with an increased consumption of SFA. There is additionally a requirement for creating national and international databases on the dietary fat intake in all age categories. Such information, which is as yet missing, will be very 
useful in considering the connection between dietary components and the etiology of NCDs in Lebanon.

Author Contributions: M.H.: Conceptualization, Data Curation, Formal Analysis, Investigation, Methodology, Project Administration, Supervision, Validation, Writing-Original Draft Preparation; E.Z.: Conceptualization, Methodology, Project Administration, Writing-Original Draft Preparation, Writing-Review \& Editing; A.R.: Methodology, Project Administration, Supervision, Writing—Review \& Editing; I.S.: Methodology, Project Administration, Supervision, Writing-Review \& Editing; A.A.-J.: Data Curation, Methodology, Project Administration, Supervision, Validation, Writing-Review \& Editing. All authors have read and agreed to the published version of the manuscript.

Funding: This research did not receive any specific grant from funding agencies in the public, commercial, or not-for-profit sectors.

Institutional Review Board Statement: Not applicable.

Informed Consent Statement: Not applicable.

Data Availability Statement: All the study data are reported in this paper.

Acknowledgments: The authors would like to thank Joseph Matta and the laboratory technician Halim El Bayeh at the Industrial Research Institute, as well as the research assistants Nadia Hallak and Iman Kheir at the Lebanese University. The authors are grateful to Carla Ibrahim, student at the Holy Spirit University of Kaslik, for her assistance in drafting the manuscript. The authors confirm the approval of the acknowledged persons to be acknowledged.

Disclaimer: The authors alone are responsible for the views expressed in this article and they do not necessarily represent the views, decisions or policies of WHO or the other institutions with which the authors are affiliated.

Conflicts of Interest: The authors declare no conflict of interest.

\section{References}

1. Jia, X.; Liu, J.; Chen, B.; Jin, D.; Fu, Z.; Liu, H.; Du, S.; Popkin, B.; Mendez, M. Differences in nutrient and energy contents of commonly consumed dishes prepared in restaurants v. at home in Hunan Province, China. Public Health Nutr. 2018, 21, 1307-1318. [CrossRef] [PubMed]

2. Bennett, J.; Kontis, V.; Mathers, C.D.; Guillot, M.; Rehm, J.; Chalkidou, K.; Kengne, A.P.; Carrillo-Larco, R.M.; A Bawah, A.; Dain, K.; et al. NCD Countdown 2030: Pathways to Achieving Sustainable Development Goal Target 3.4. Lancet 2020, 396, 918-934. [CrossRef]

3. Goal 11: Sustainable Cities and Communities. Available online: https://www.lb.undp.org/content/lebanon/en/home/ sustainable-development-goals/goal-11-sustainable-cities-and-communities.html (accessed on 9 September 2020).

4. Lebanon Demographics Profile 2019. Available online: https://www.indexmundi.com/lebanon/demographics_profile.html (accessed on 8 September 2020).

5. Sibai, A.M.; Nasreddine, L.; Mokdad, A.; Adra, N.; Tabet, M.; Hwalla, N. Nutrition transition and cardiovascular disease risk factors in Middle East and North Africa countries: Reviewing the evidence. Ann. Nutr. Metab. 2010, 57, 193-203. [CrossRef] [PubMed]

6. Nasreddine, L.; Shatila, H.; Itani, L.; Hwalla, N.; Jomaa, L.; Naja, F. A traditional dietary pattern is associated with lower odds of overweight and obesity among preschool children in Lebanon: A cross-sectional study. Eur. J. Nutr. 2019, 58, 91-102. [CrossRef]

7. Tueni, M.; Mounayar, A. Study for Assessment of Traditional Food Intake in Lebanon. 2003. Available online: https://eventscal. lau.edu.lb/conferences/nfrd2014/abstracts/nutrition/nutrition-abstract18a.pdf (accessed on 1 September 2020).

8. Batal, M.; Hunter, E. Traditional Lebanese recipes based on wild plants: An answer to diet simplification? Food Nutr. Bull. 2007, 28, S303-S311. [CrossRef] [PubMed]

9. Akkawi, A.; Khabsa, J.; Noubani, A.; Jamali, S.; Sibai, A.M.; Lotfi, T. Non-communicable diseases research output in the Eastern Mediterranean region: An overview of systematic reviews. BMC Med. Res. Methodol. 2020, 20, 68. [CrossRef]

10. Joris, P.J.; Mensink, R.P. Role of cis-Monounsaturated Fatty Acids in the Prevention of Coronary Heart Disease. Curr. Atheroscler. Rep. 2016, 18, 38. [CrossRef]

11. Schwingshackl, L.; Strasser, B.; Hoffmann, G. Effects of monounsaturated fatty acids on glycaemic control in patients with abnormal glucose metabolism: A systematic review and meta-analysis. Ann. Nutr. Metab. 2011, 58, 290-296. [CrossRef]

12. Abedi, E.; Sahari, M.A. Long-chain polyunsaturated fatty acid sources and evaluation of their nutritional and functional properties. Food Sci. Nutr. 2014, 2, 443-463. [CrossRef] 
13. Nguyen, Q.V.; Malau-Aduli, B.S.; Cavalieri, J.; Malau-Aduli, A.E.O.; Nichols, P.D. Enhancing Omega-3 Long-Chain Polyunsaturated Fatty Acid Content of Dairy-Derived Foods for Human Consumption. Nutrients 2019, 11, 743. [CrossRef]

14. Wanders, A.; Zock, P.; Brouwer, I. Trans Fat Intake and Its Dietary Sources in General Populations Worldwide: A Systematic Review. Nutrients 2017, 9, 840. [CrossRef]

15. Issa, C.; Salameh, P.; Batal, M.; Vieux, F.; Lairon, D.; Darmon, N. The Nutrient Profile of Traditional Lebanese Composite Dishes: Comparison with Composite Dishes Consumed in France. Int. J. Food Sci. Nutr. 2009, 60, 285-295. [CrossRef]

16. Hoteit, M.; Zoghbi, E.; Rady, A.; Shankiti, I.; Al-Jawaldeh, A. Development of a Lebanese food exchange system based on frequently consumed Eastern Mediterranean traditional dishes and Arabic sweets. F1000Research 2021, 10, 12. [CrossRef] [PubMed]

17. Hoteit, M.; Zoghbi, E.; Al Iskandarani, M.; Rady, A.; Shankiti, I.; Matta, J.; Al-Jawaldeh, A. Nutritional value of the Middle Eastern diet: Analysis of total sugar, salt, and iron in Lebanese traditional dishes. F1000Research 2020, 9, 1254. [CrossRef]

18. Latimer, G.W. Official Methods of Analysis of AOAC International, 21st ed.; Association of Official Analytical Chemists: Gaithersburg, MD, USA, 2019.

19. Chen, J.; Liu, H. Nutritional Indices for Assessing Fatty Acids: A Mini-Review. Int. J. Mol. Sci. 2020, 21, 5695. [CrossRef] [PubMed]

20. Label Claims for Conventional Foods and Dietary Supplements (2018). Available online: https://www.fda.gov/food/foodlabeling-nutrition/label-claims-conventional-foods-and-dietary-supplements (accessed on 8 September 2020).

21. World Health Organisation. Healthy Diet. Available online: https://www.who.int/news-room/fact-sheets/detail/healthy-diet (accessed on 17 April 2021).

22. Bawadi, H.A.; Al-Sahawneh, S.A. Developing a meal-planning exchange list for traditional dishes in jordan. J. Am. Diet. Assoc. 2008, 108, 840-846. [CrossRef] [PubMed]

23. Al Faris, N. Nutritional Evaluation of Selected Traditional Foods Commonly Consumed in Saudi Arabia. J. Food Nutr. Res. 2017, 5, 168-175. [CrossRef]

24. Pellet, P.L.; Shadarevian, S. Food Composition Tables for Use in the Middle East, 2nd ed.; American University of Beirut: Beirut, Lebanon, 1970.

25. Musaiger, A.; Abuirmeileh, N. Food consumption patterns of adults in the United Arab Emirates. J. R. Soc. Promot. Health 1998, 118, 146-150. [CrossRef]

26. Musaiger, A. Food composition tables for kingdom of Bahrain. In INFOODS Regional Database Center, 1st ed.; Arab Center for Nutrition: Manama, Bahrain, 2011.

27. Dashti, B.H.; Al-Awadi, F.; Khalafawi, M.S.; Al-Zenki, S.; Sawaya, W. Nutrient contents of some traditional Kuwaiti dishes: Proximate composition, and phytate content. Food Chem. 2001, 74, 169-175. [CrossRef]

28. World Health Organization; Brouwer, I.A. Effect of Trans-Fatty Acid Intake on Blood Lipids and Lipoproteins: A Systematic Review and Meta-Regression Analysis; World Health Organization: Geneva, Switzerland, 2016. Available online: https://apps.who.int/iris/ handle/10665/246109 (accessed on 7 March 2021).

29. Zong, G.; Li, Y.; Sampson, L.; Dougherty, L.; Willett, W.; Wanders, A.; Alssema, M.; Zock, P.; Hu, F.; Sun, Q. Monounsaturated fats from plant and animal sources in relation to risk of coronary heart disease among US men and women. Am. J. Clin. Nutr. 2018, 107, 445-453. [CrossRef] [PubMed]

30. World Health Organization. Noncommunicable Diseases Country Profiles; World Health Organization: Geneva, Switzerland, 2018. Available online: www.who.int/news-room/fact-sheets/detail/noncommunicable-diseases (accessed on 15 February 2021).

31. Virani, S.S.; Alonso, A.; Benjamin, E.J.; Bittencourt, M.S.; Callaway, C.W.; Carson, A.P.; Chamberlain, A.M.; Chang, A.R.; Cheng, S.; Delling, F.N.; et al. American Heart Association Council on Epidemiology and Prevention Statistics Committee and Stroke Statistics Subcommittee. Heart Disease and Stroke Statistics-2020 Update: A Report from the American Heart Association. Circulation 2020, 141, e139-e596. [CrossRef] [PubMed]

32. Sawaya, W.; Al-Awadhi, F.; Naeemi, I.; Sayegh, A.; Ahmad, N.; Khalafawi, S. Dietary fat profiles of composite dishes of the Arabian Gulf country of Kuwait. J. Food Compos. Anal. 1998, 11, 200-211. [CrossRef]

33. Brown, H.M.; Rollo, M.E.; de Vlieger, N.M.; Collins, C.E.; Bucher, T. Influence of the nutrition and health information presented on food labels on portion size consumed: A systematic review. Nutr. Rev. 2018, 76, 655-677. [CrossRef] [PubMed] 